
Yanli Zhang and Mingli Jiao*

\title{
How the hindered amines affect the microstructure and mechanical properties of nitrile-butadiene rubber composites
}

https://doi.org/10.1515/epoly-2020-0002

Received August 29, 2019; accepted October 11, 2019.

Abstract: Different hindered amines, GW-622 and GW-944, were added to a nitrile-butadiene rubber (NBR) matrix to prepare a hybrid damping material. The microstructure, compatibility, and dynamic mechanical properties of the hindered amine/NBR composites were investigated using Fourier transform infrared (FTIR) spectroscopy, scanning electron microscope (SEM), differential scanning calorimetry (DSC), and dynamic thermomechanical analysis (DMA). The FTIR results showed that hydrogen bonds formed between the hindered amine molecules and the NBR matrix. The SEM and DSC results showed that both GW-622 and GW-944 had partial compatibility with the NBR matrix, and a two-phase structure appeared. The effective damping temperature ranges of the hindered amine/NBR composites were narrow at room temperature and broad at higher temperatures with increasing amounts of GW-622 and GW-944. Comparatively, the damping effect from the addition of GW-944 molecules was more clearly. The present work provides a theoretical basis for the preparation of optimum damping rubber materials.

Keywords: organic hybrid; hydrogen bond; damping properties; hindered amines; nitrile-butadiene rubber

\footnotetext{
* Corresponding authors: Meng Song and Mingli Jiao, School of Materials and Chemical Engineering, Zhongyuan University of Technology, Zhengzhou 450007, China, email: chengsimengyin@126.com; johnml@163.com Qi Qin, Guomin Yu, Zhongzhu Liu, Haiyan Pei and Yanli Zhang, School of Materials and Chemical Engineering, Zhongyuan University of Technology, Zhengzhou 450007, China Xiujuan Wang, Key Laboratory of Rubber-plastics, Ministry of Education/Shandong Provincial Key Laboratory of Rubber-Plastics, Qingdao University of Science \& Technology

Sizhu Wu, State Key Laboratory of Organic-Inorganic Composites, Beijing University of Chemical Technology, Beijing 100029, China
}

\section{Introduction}

Rubber damping materials, with a unique viscoelasticity, havebeen widelyusedin precisionmachines, asmechanical absorbers and for submarine noise elimination $(1,2)$. The final performance of rubber damping materials, an important strategic resource, is increasingly demanding, so how to prepare high-performance rubber damping materials has become a research hotspot $(3,4)$. The general damping factor of a pure rubber matrix is small (the $\tan \delta$ value $<1.0)$, and the glass transition temperature $\left(T_{g}\right)$ range is very narrow (only $20^{\circ} \mathrm{C} 30^{\circ} \mathrm{C}$ ) $(5,6)$. The effective damping temperature occurs at low temperatures below room temperature. In recent years, many scholars have been committed to modifying pure rubber substrates to achieve the required damping properties. The following methods are usually used: blending (7), copolymerization (8), interpenetrating networks (IPN) $(9,10)$ and organic hybrid damping materials $(11,12)$. Of all these methods, the organic hybrid damping materials are more novel, and are used in this study.

Organic hybridization refers to the addition of small organic molecules containing polar functional groups to a polar rubber matrix. Hydrogen bond networks run through the matrix and form between the polar functional groups on the large macromolecules and small molecules (13). Compared with the van der Waals force, the interaction of hydrogen bonds is stronger and reversible. They can be destroyed and regenerated under the action of an external force field and temperature field, thus absorbing a large amount of energy and producing a high damping dissipation (14). Chinese scholar Wu added small organic molecules, such as hindered phenol AO-80 and accelerator $\mathrm{DZ}$, to polar substrates, such as chlorinated polyethylene (CPE) and polyacrylic ester (ACR), using the reversible hydrogen bonds formed between small organic molecules and polymer substrates to obtain organic hybrid damping materials with high loss factors $(15,16)$. This approach attracted the interest of many researchers and is thought 
to have pioneered a new concept for the preparation of high-performance damping materials. Zhao et al. studied hindered phenol AO-80/nitrile-butadiene rubber (NBR) composites, and found that organic hybrid damping materials obtained by this method have outstanding performance than compared with IPN and other methods (17). Zhao et al, also prepared hindered phenol AO-60/NBR composites and hindered phenol AO-70/NBR composites with excellent damping properties $(18,19)$.

In this study, NBR was selected as a substrate material for organic hybridization because of its good damping properties. Two kinds of hindered amines with different numbers of polar functional groups and steric hindrance were added to the same rubber substrate. The microscopic structure and the hydrogen bond interaction were investigated by Fourier transform infrared (FTIR) spectroscopy and differential scanning calorimetry (DSC). Dynamic thermomechanical analysis (DMA) was used to study the damping properties of the two hybrid systems. The goal is to form strong hydrogen bond between hindered amines and NBR to improve the damping properties of the material.

\section{Experimental}

\subsection{Materials}

NBR (N220S) with an acrylonitrile mass fraction of $41 \%$ was provided by Japan Synthetic Rubber Co., Ltd. (Tokyo, Japan). Hindered amines GW-622 and GW-944, as powders, were purchased from Beijing Additives Institute (Beijing, China). The chemical structures of GW-622 and GW-944 are shown in Figure 1. Other rubber additives used in the study were purchased in China and used without further purification.

As a common hindered amine antioxidant, GW-622 with hydroxyl groups and other polar functional groups (eater or amino groups) or GW-944 with amino and imino groups can form intermolecular interactions with NBR, which likely improves the damping properties of the NBR matrix.

\subsection{Preparation of hindered amine/NBR composites}

Hindered amine/NBR rubber composites were prepared according to the following procedure.

1. The NBR was first plasticized on a $\varphi 152.4 \mathrm{~mm}$ two-roll mill at room temperature for $3 \mathrm{~min}$, and GW-622 was added to the NBR with mass ratios of $0 / 100,11 / 100$,
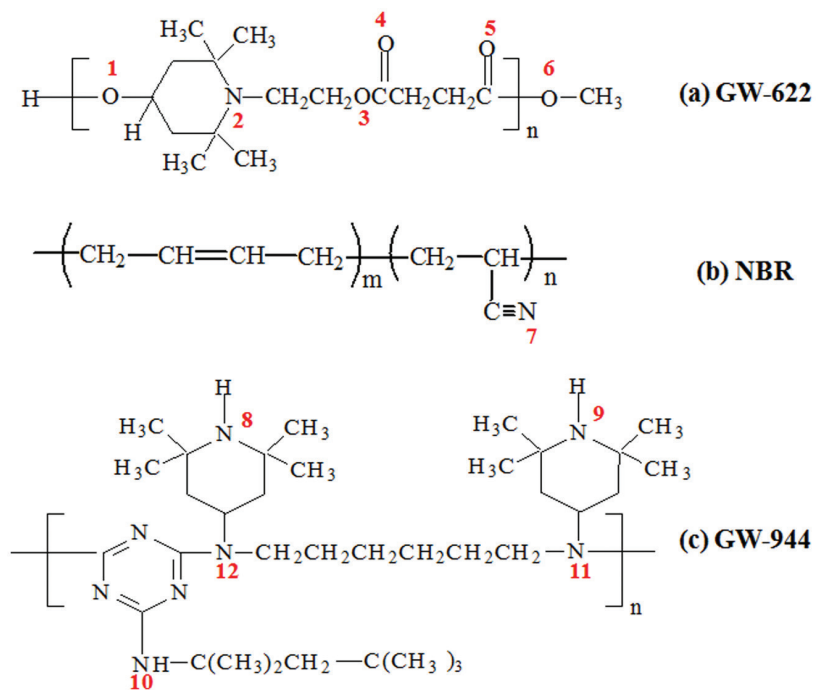

Figure 1: Molecular structures of (a) GW-622, (b) NBR and (c) GW-944.

21/100, 43/100, 64/100, and 86/100 (GW-944 was added to the NBR matrix with mass ratios of $0 / 100$, 11/100, 22/100, 44/100, 67/100, and 89/100). These composites were then kneaded at room temperature for $5 \mathrm{~min}$ to prepare the first-stage GW-622/NBRa (or GW-944/NBRa) composites.

2. The hindered amine/NBRa composites were kneaded on a two-roll mill at $130^{\circ} \mathrm{C}$ for $5 \mathrm{~min}$ to fully fuse the hindered amine molecules before the composites were gradually cooled to room temperature to form the second-stage hindered amine/NBRb composites.

3. The hindered amine/NBRb composites were then blended with compounding and crosslinking additives, including $5.0 \mathrm{phr}$ of zinc oxide, $2.0 \mathrm{phr}$ of stearic acid, $0.5 \mathrm{phr}$ of diphenyl guanidine, $2.0 \mathrm{phr}$ of sulfur, $0.2 \mathrm{phr}$ of tetramethylthiuram disulfide and $0.5 \mathrm{phr}$ of dibenzothiazole disulfide. The composites were then kneaded on a two-roll mill at room temperature for $10 \mathrm{~min}$.

4. Finally, the composites were hot-pressed and vulcanized at $160^{\circ} \mathrm{C}$ under a pressure of $15 \mathrm{MPa}$ for different periods of time, and then naturally cooled down to room temperature to prepare the hindered amine/NBR samples.

\subsection{Characterization}

FTIR measurements were conducted on a Nicolet 8700 FTIR spectrometer made by Thermo Fisher Scientific Inc. (USA). The FTIR spectra were obtained by scanning the specimens in a wavenumber range from $500 \mathrm{~cm}^{-1}$ 
to $4000 \mathrm{~cm}^{-1}$ for 32 scans at a resolution of $8 \mathrm{~cm}^{-1}$. The FTIR spectra of the hindered amine/NBR composites were acquired from film specimens with a thickness of approximately $1 \mathrm{~mm}$ by using the attenuated total reflection (ATR) technique. The FTIR spectra of the as-received GW-622 (or GW-944) powder were acquired by using ultrathin disk specimens pressed from GW-622 (or GW-944) ground in anhydrous potassium bromide (KBr).

Scanning electron microscopy (SEM) images were taken of the fracture surfaces of the hindered amine/NBR composites using a Hitachi S-4800 (Japan) scanning electron microscope. All SEM samples were cryogenically fractured by quenching in liquid nitrogen.

The DSC measurements were performed on a TGA/DSC calorimeter made by Mettler-Toledo Co (Switzerland). Samples weighing approximately $10 \mathrm{mg}$ and sealed in aluminum were heated from $-60^{\circ} \mathrm{C}$ to $150^{\circ} \mathrm{C}$ at a heating rate of $10^{\circ} \mathrm{C} / \mathrm{min}$ under a nitrogen atmosphere.

The DMA measurements were conducted in tension mode by using a VA 3000 dynamic mechanical analyzer made by Rheometric Scientific Inc. (USA). The samples were $15 \mathrm{~mm}$ long, $10 \mathrm{~mm}$ wide, and approximately $2 \mathrm{~mm}$ thick. The temperature dependence of the loss factor $(\tan \delta)$ for various samples was measured between $-100^{\circ} \mathrm{C}$ and $250^{\circ} \mathrm{C}$ at a constant frequency of $10 \mathrm{~Hz}$ and a heating rate of $5^{\circ} \mathrm{C} / \mathrm{min}$.

\section{Results and discussion}

\subsection{Hydrogen bonds in hindered amine/NBR composites}

To examine the intermolecular interactions between the hindered amines and NBR rubber matrix, FTIR measurements of pure hindered amines and different hindered amine/NBR composites with various mass ratios were obtained. The FTIR spectra of the GW-622, GW-944, and GW-622/NBR and GW-944/NBR composites are shown in Figure 2. In Figure 2a for the GW-622 small molecule, two obvious absorption peaks appear at $3542 \mathrm{~cm}^{-1}$ and $3457 \mathrm{~cm}^{-1}$, which were assigned to the free hydroxyls and the hydrogen bond interactions (O-H...O hydrogen bonds) between GW-622 molecules, respectively (17,20). In Figure 2c, given the GW-622 molecules added to the NBR matrix, a broad
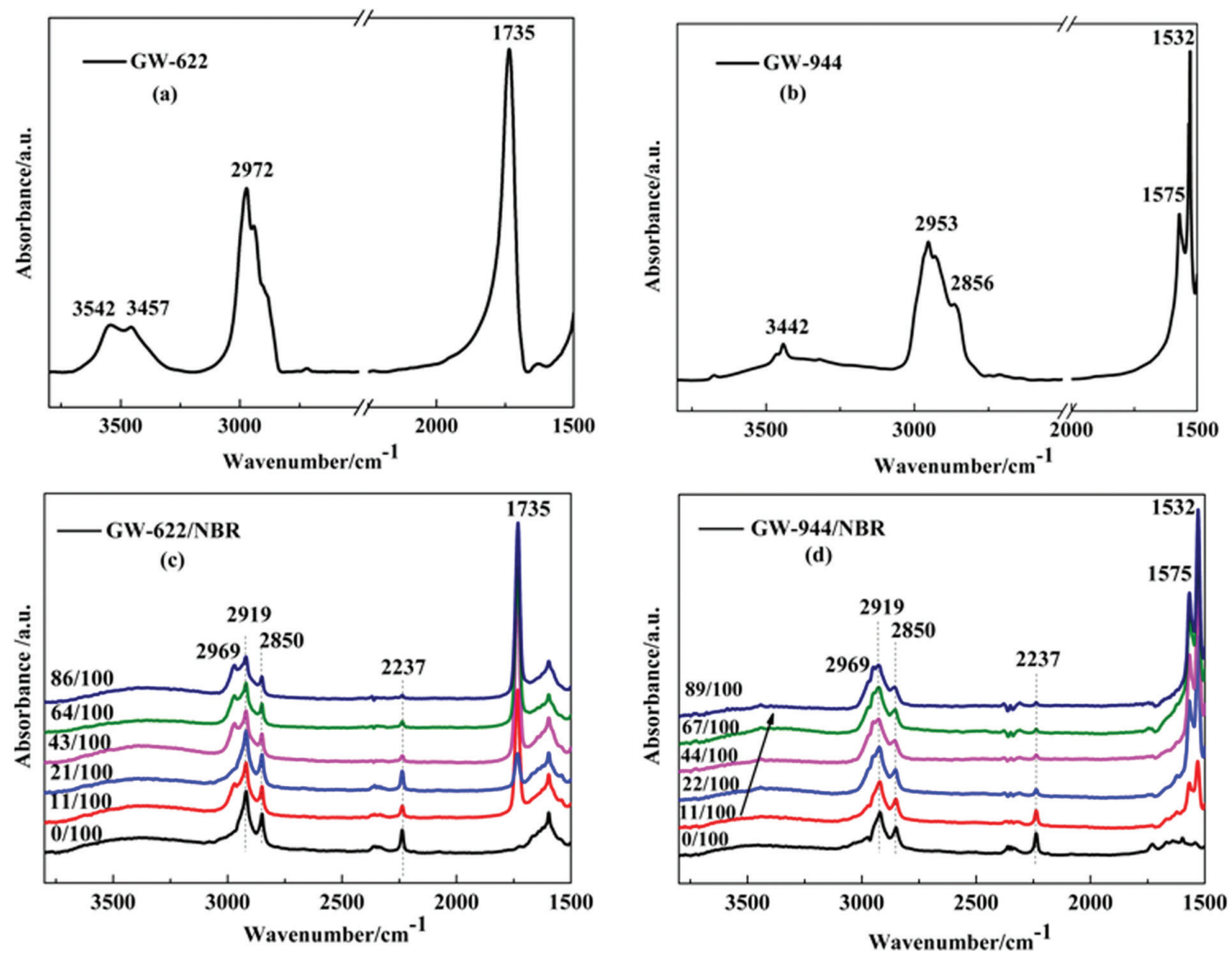

Figure 2: FTIR spectra of (a) GW-622, (b) GW-944, (c) GW-622/NBR and (d) GW-944/NBR composites with various compositions. 
peak appears in the wavenumber range of $3150-3550 \mathrm{~cm}^{-1}$, which was characterized as the hydrogen bond between the $-\mathrm{OH}$ groups of GW-622 (Figure 1a: 1) and the $-\mathrm{CN}$ groups of NBR (Figure 1b: 7). Moreover, in Figure 2c, the absorption of the $-\mathrm{CN}$ groups at wavenumber $2237 \mathrm{~cm}^{-1}$ is weakened with increasing GW-622 content, which suggests hydrogen bonding with an increasing strength between the $-\mathrm{OH}$ group and the $-\mathrm{CN}$ group.

The same phenomenon exists in the GW-944/NBR composites. In Figure $2 \mathrm{~b}$ for the GW-944 molecule, obvious absorption peaks appear at $3442 \mathrm{~cm}^{-1}$, which were assigned to subamino - $\mathrm{NH}$ - groups. A redshift phenomenon occurs from $3550 \mathrm{~cm}^{-1}$ to $3300 \mathrm{~cm}^{-1}$ with increasing GW-944 content in the GW-944/NBR composites, indicating hydrogen bond formation between the $-\mathrm{NH}-$ group (Figure 1c: 8 , 9 , and 10) and the $-\mathrm{CN}$ group (Figure 1b: 7) $(21,22)$. The redshift phenomenon becomes obvious as the hydrogen bond interaction increases in strength (23). Moreover, the absorption of the $-\mathrm{CN}$ groups at the wavenumber $2237 \mathrm{~cm}^{-1}$ is weakened with increasing GW-944 content, which can also provide evidence of hydrogen bond formation.

\subsubsection{SEM observation for hindered amine/NBR composites}

Figure 3 shows SEM micrographs of the fracture surface of the pure NBR matrix and the hindered amine/NBR composites with different GW-622 and GW-944 contents. In Figure 3a, the pure NBR matrix has a smooth fracture surface with bright $\mathrm{ZnO}$ particles, which was confirmed
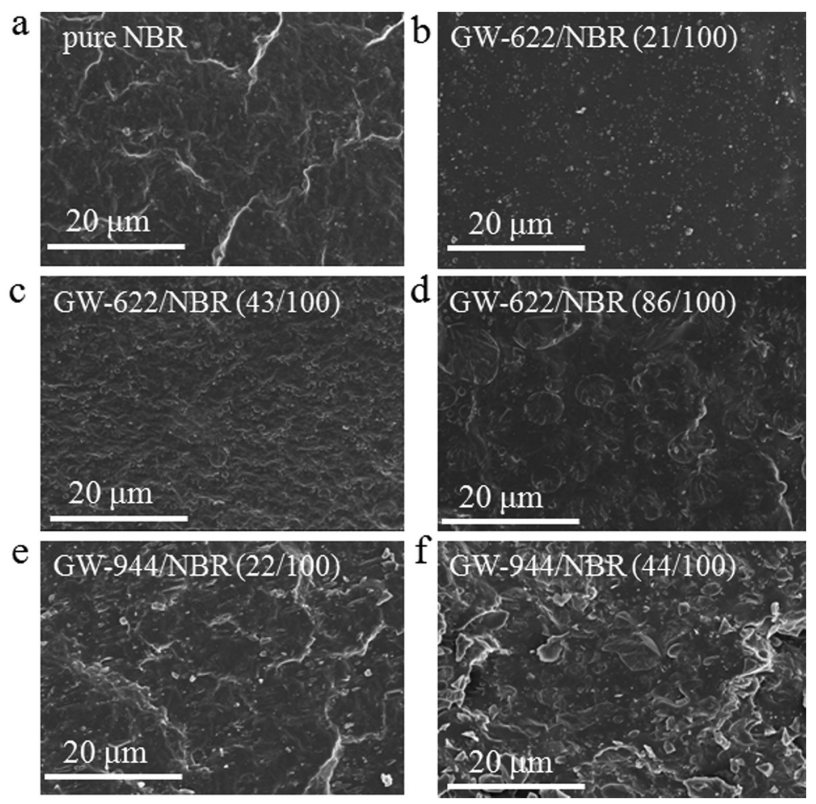

Figure 3: SEM image of hindered amine/NBR composites. by element analysis attached to the scanning electron microscope (24). The fracture surface of the GW-622/NBR composite is homogeneous at a GW-622 content of $21 \mathrm{phr}$, because most of the GW-622 molecules dissolved and achieved good dispersion in the NBR matrix. As the GW-622 content exceeds $21 \mathrm{phr}$, GW-622 has partial miscibility and phase separates with the NBR matrix. There appear to be numerous holes created by the removal of GW-622 molecules from the GW-622/NBR fracture surface. Similarly, the addition of GW-944 over $22 \mathrm{phr}$ also causes the appearance of two-phasestructures in the GW-944/NBR composites, which is even more substantial than that in the GW-622/NBR composites. This phenomenon is also confirmed in the following DSC and DMA analyses.

\subsection{Glass transition temperature $\left(T_{g}\right)$ in hindered amine/NBR composites}

The compatibility of blends can usually be characterized by the $T_{g}$. If the blending system has only one $T_{g}$, the compatibility is good. Otherwise, two glass transitions indicate poor compatibility (25). Figure 4 shows the DSC curves of two small hindered amine molecules and hindered amine/NBR composites. As shown in Figure 4a, the $T_{g}$ values of the pure GW-622 molecules and GW-944 molecules are $67.6^{\circ} \mathrm{C}$ and $84.8^{\circ} \mathrm{C}$, respectively. In Figures $3 \mathrm{~b}$ and $3 \mathrm{c}$, the pure NBR matrix has only one $T_{g}$. As the GW-622 and GW-944 molecules are added, the $T_{g}$ of the GW-622/NBR and GW-944/NBR composites increases to more than that of the pure NBR matrix, which can be verified from the $T_{g}$ fitting curve or different GW-622/NBR and GW-944/NBR composites in Figure 4d. The increase in $T_{g}$ is due to the contribution of hydrogen bond formation in the composites, which is consistent with the FTIR results above (22). The formation of hydrogen bond networks limits the movements of large polymer chains, increasing the $T_{g}$ of hindered amine/NBR composites. When the addition of GW-622 is above $21 \mathrm{phr}$, two $T_{g} \mathrm{~s}$ appear in the GW-622/NBR composites, indicating a two-phase structure and poor compatibility between the NBR matrix and the GW-622 molecules. At this time, the small GW-622 molecule reached the saturation state in the NBR matrix. The $T_{g}$ of the amorphous GW-622 accumulated in the NBR matrix occurs at $54.5^{\circ} \mathrm{C}$.

\subsection{Dynamic mechanical properties of hindered amine/NBR composites}

DMA was conducted to study the compatibility and damping properties of the hindered amine/NBR 

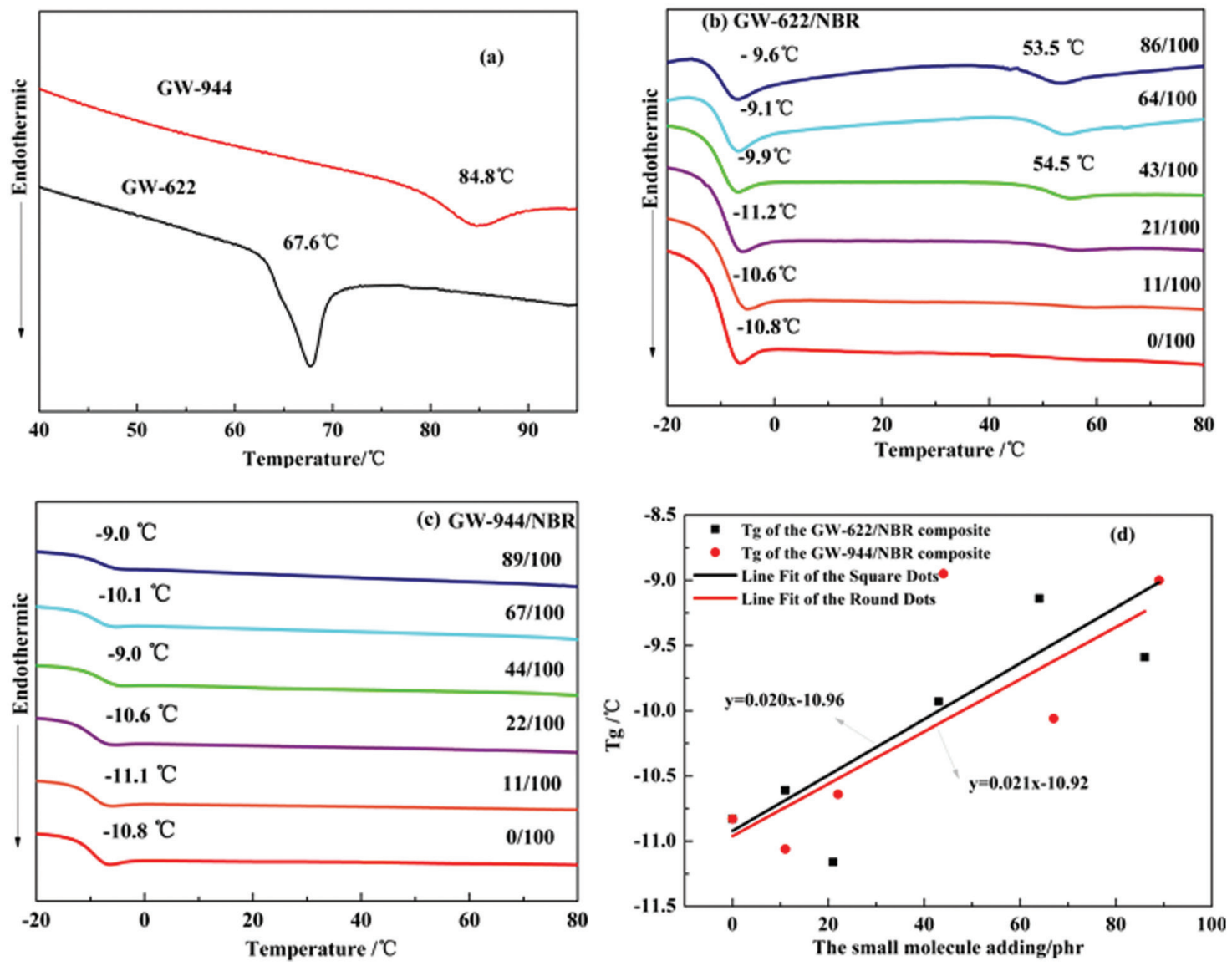

Figure 4: DSC thermograms of (a) hindered amines, (b) GW-622/NBR composites and (c) GW-944/NBR composites; (d) the fitting curves of the Tg of different composites.
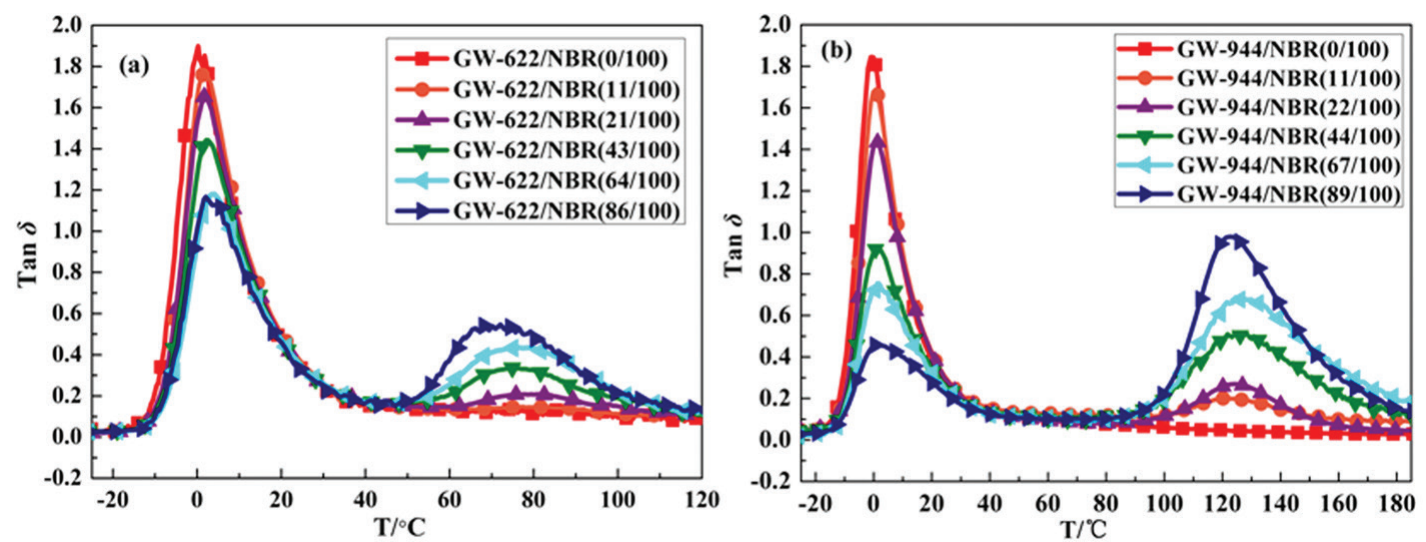

Figure 5: Temperature dependence of loss tangent (tanס): (a) GW-622/NBR composite and (b) GW-944/NBR composite.

composites $(26,27)$. Figure 5 shows the temperature dependence of the loss tangent $(\tan \delta)$ for the GW-622/NBR and GW-944/NBR composites with different mass ratios. The $\tan \delta$ reflects the ratio of the dissipated energy in one deformation cycle to the energy accumulated during the same cycle, which is usually used to characterize the damping properties of materials. The evaluation criteria of damping materials include two aspects: the value of the $\tan \delta$ peak during the glass transition and the temperature range for which $\tan \delta \geq 0.3$. The $\tan \delta$ values of the materials with good damping performance are relatively large, and the peak area is wide.

From Figure 5 shows that the pure NBR matrix has only one $\tan \delta$ peak. With the addition of small hindered 
Table 1: Damping properties of the GW-622/NBR composite with different GW-622 molecule contents.

\begin{tabular}{|c|c|c|c|c|c|c|c|c|}
\hline \multirow{3}{*}{ GW-622/NBR } & \multicolumn{4}{|c|}{$\mathrm{T}<50\left({ }^{\circ} \mathrm{C}\right)$} & \multicolumn{4}{|c|}{$\mathrm{T}>50\left({ }^{\circ} \mathrm{C}\right)$} \\
\hline & \multirow[t]{2}{*}{$\begin{array}{c}\tan \delta \text { peak } \\
\text { position }\left({ }^{\circ} \mathrm{C}\right)\end{array}$} & \multirow[t]{2}{*}{$\begin{array}{c}\tan \delta \text { peak } \\
\text { height }\end{array}$} & \multicolumn{2}{|c|}{$\begin{array}{c}\text { Temperature } \\
\text { range }>0.3\left({ }^{\circ} \mathrm{C}\right)\end{array}$} & \multirow[t]{2}{*}{$\begin{array}{c}\tan \delta \text { peak } \\
\text { position }\left({ }^{\circ} \mathrm{C}\right)\end{array}$} & \multirow[t]{2}{*}{$\begin{array}{c}\tan \delta \text { peak } \\
\text { height }\end{array}$} & \multicolumn{2}{|c|}{$\begin{array}{c}\text { Temperature } \\
\text { range }>0.3\left({ }^{\circ} \mathrm{C}\right)\end{array}$} \\
\hline & & & $\Delta T$ & TA & & & $\Delta \mathrm{T}$ & TA \\
\hline $0 / 100$ & 0.2 & 1.90 & 34.55 & 33.36 & - & - & - & - \\
\hline $11 / 100$ & 1.7 & 1.77 & 34.4 & 31.91 & 80.95 & 0.15 & - & - \\
\hline $21 / 100$ & 1.7 & 1.65 & 34.05 & 30.12 & 80.9 & 0.21 & - & - \\
\hline $43 / 100$ & 2.55 & 1.44 & 32.9 & 26.99 & 74.9 & 0.34 & 15 & 4.86 \\
\hline $64 / 100$ & 4.1 & 1.18 & 32.1 & 23.31 & 76.55 & 0.44 & 29.3 & 11.48 \\
\hline $86 / 100$ & 2.05 & 1.17 & 32.05 & 23.17 & 72.1 & 0.55 & 34.4 & 15.70 \\
\hline
\end{tabular}

Table 2: Damping properties of the GW-944/NBR composite with different GW-944 molecule contents.

\begin{tabular}{|c|c|c|c|c|c|c|c|c|}
\hline \multirow{3}{*}{ GW-944/NBR } & \multicolumn{4}{|c|}{$\mathrm{T}<50\left({ }^{\circ} \mathrm{C}\right)$} & \multicolumn{4}{|c|}{$\mathrm{T}>50\left({ }^{\circ} \mathrm{C}\right)$} \\
\hline & \multirow[t]{2}{*}{$\begin{array}{c}\tan \delta \text { peak } \\
\text { position }\left({ }^{\circ} \mathrm{C}\right)\end{array}$} & \multirow[t]{2}{*}{$\begin{array}{c}\tan \delta \text { peak } \\
\text { height }\end{array}$} & \multicolumn{2}{|c|}{$\begin{array}{c}\text { Temperature } \\
\text { range }>0.3\left({ }^{\circ} \mathrm{C}\right)\end{array}$} & \multirow[t]{2}{*}{$\begin{array}{c}\tan \delta \text { peak } \\
\text { position }\left({ }^{\circ} \mathrm{C}\right)\end{array}$} & \multirow[t]{2}{*}{$\begin{array}{c}\tan \delta \text { peak } \\
\text { height }\end{array}$} & \multicolumn{2}{|c|}{$\begin{array}{c}\text { Temperature } \\
\text { range }>0.3\left({ }^{\circ} \mathrm{C}\right)\end{array}$} \\
\hline & & & $\Delta \mathrm{T}$ & TA & & & $\Delta T$ & TA \\
\hline $0 / 100$ & 0.2 & 1.90 & 34.55 & 33.36 & - & - & - & - \\
\hline $11 / 100$ & 0.7 & 1.69 & 32.90 & 30.12 & 120.25 & 0.20 & - & - \\
\hline $22 / 100$ & 1.35 & 1.43 & 32.75 & 26.99 & 124.10 & 0.27 & - & - \\
\hline $44 / 100$ & 1.4 & 0.93 & 28.65 & 18.01 & 124.50 & 0.51 & 43.6 & 36.46 \\
\hline $67 / 100$ & 1.35 & 0.75 & 26.90 & 14.82 & 124.50 & 0.69 & 58.6 & 45.13 \\
\hline $89 / 100$ & 2.05 & 0.46 & 23.15 & 9.25 & 122.50 & 0.98 & 55.85 & 45.94 \\
\hline
\end{tabular}

amine molecules, two $\tan \delta$ peaks gradually appear in the composites, indicating that a two-phase structure appears in the composites, and the small hindered amine molecules reach saturation in the matrix and begin to accumulate. We can also find this phenomenon in the SEM and DSC results above.

Figure 5a shows that the $\tan \delta$ peak of GW-622/NBR gradually shifts to higher temperatures with increasing GW-622 content, which is primarily due to the formation of hydrogen bonds between the NBR matrix and the GW-622 molecules. When the addition amount of GW-622 molecules is less than $11 \mathrm{phr}$, the composite has only one $\tan \delta$ peak, indicating a good compatibility of the GW-622 molecules with the NBR matrix. However, as the GW-622 content exceeds $21 \mathrm{phr}$, two $\tan \delta$ peaks appear, implying phase separation. The excessive GW-622 molecules accumulated, resulting in the emergence of a second $\tan \delta$ peak. Table 1 shows the values of the two $\tan \delta$ peaks in the GW-622/NBR composites with different GW-622 contents. As the GW-622 content increases from 0 to 86 phr, the first $\tan \delta$ peak decreases and gradually shifts to higher temperatures. The value of the first $\tan \delta$ peak decreases from 1.90 to 1.17 , the damping temperature range $(\Delta \mathrm{T})$ at low temperature $\left(\mathrm{T}<50^{\circ} \mathrm{C}\right)$ decreases from $34.55^{\circ} \mathrm{C}$ to $32.05^{\circ} \mathrm{C}$, and the peak area (TA) also decreases from 33.36 to 23.17 , indicating that the addition of GW-622 small molecules reduced the damping performance of the NBR matrix at room temperature. However, at higher temperatures, the second $\tan \delta$ peak of GW-622/NBR gradually shifts from $80.95^{\circ} \mathrm{C}$ to $72.1^{\circ} \mathrm{C}$, and the second $\tan \delta$ value increases from 0.15 to 0.55 . Moreover, the temperature range for $\tan \delta \geq 0.3$ and TA value for high temperature damping also gradually increases in size. From the above, the addition of the GW-622 molecule reduces the damping performance of the NBR composite at room temperature and increases the damping performance of the NBR composite at high temperatures. This is the result of the combined interactions of hydrogen bond formation and aggregation of excess small GW-622 molecules. Hydrogen bond formation limits the movement of NBR chains and causes more energy dissipation. However, the aggregation of GW-622 molecules after reaching saturation in the composite results in phase separation. 

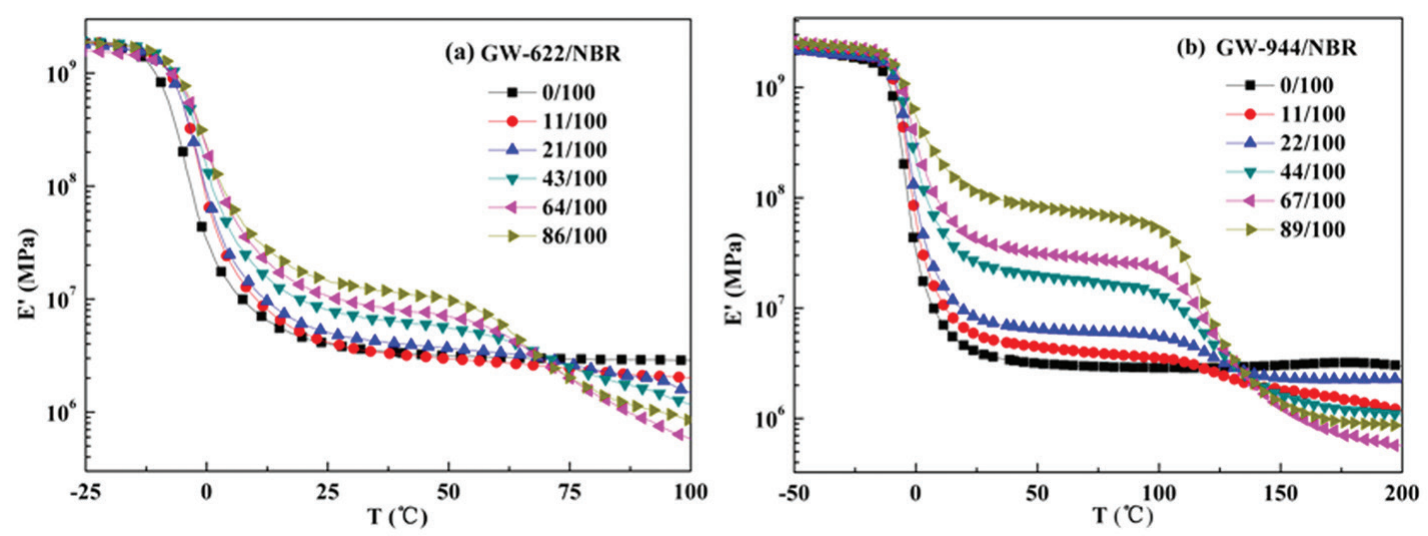

Figure 6: Temperature dependence of the storage modulus (E') values of (a) GW-622/NBR composites and (b) GW-944/NBR composites.

As shown in Figure 5b and Table 2, when small GW-944 molecules are added to the NBR matrix, a similar damping performance to that of the GW-944/NBR composites with different GW-944 contents can be observed for the GW-622 /NBR composite mentioned above. In comparison, it can be seen that the addition of GW-944 molecules makes the damping performance of the NBR composite at low temperatures decline rapidly (from 1.90 to 0.46 ) and makes the damping performance at high temperatures increase (from 0.20 to 0.98 ).

Figure 6 shows the effects of hindered amine addition and temperature on the storage modulus $\left(E^{\prime}\right)$ of the hindered amine/NBR composites with different hindered amine contents. As the hindered amine content increases, the storage modulus curves display two transitions and gradually increase to a certain extent, which further proves that the hindered amine molecules have poor compatibility and strong interaction with the NBR matrix. This result is a validation of the DSC and FTIR results above.

\section{Conclusions}

In this article, we explored the microstructure, compatibility, and damping properties of GW-622/NBR and GW-944/NBR composites using FTIR spectroscopy, SEM, DSC, and dynamic mechanical analyses. The FTIR results show that hydrogen bonds form between the hindered amine molecules and the NBR matrix. The hindered amine molecule has good compatibility with the NBR matrix when the hindered amine content is less than $21 \mathrm{phr}$; otherwise, the hindered amine molecules have a partial compatibility with the NBR matrix when the hindered amine content is more than $21 \mathrm{phr}$. This prediction is confirmed by SEM, DSC, and DMA results. The addition of hindered amine molecules to the NBR matrix reduces the damping property of the hindered amine/NBR composite at room temperature and improves the damping property of it at high temperatures. In particular, the addition of GW-944 molecules results in a very clear damping effect. This work provides a theoretical basis for the preparation of high performance damping materials.

Acknowledgements: This work was supported by the National Natural Science Foundation of China (Grant Nos. 51603236, 51703114, and 51873017); the Program for Young Backbone Teachers of Zhongyuan University of Technology, China; the Program for Interdisciplinary Direction Teams in Zhongyuan University of Technology, China; the Program for Science and Technology Innovation Talents in Universities of Henan Province (No. 19HASTIT024); and the Natural Science Foundation of Shandong Province (Grant No. ZR2017BEM036).

Notes: The authors declare no competing financial interest.

\section{References}

1. Geethamma V.G., Asaletha R., Kalarikkal N., Thomas S., Vibration and sound damping in polymers. Resonance, 2014, 19(9), 821-833.

2. Song M., Qin Q., Zhu J., Yu G.M., Wu S.Z., Jiao M.L., PressureVolume-Temperature Properties and Thermophysical Analyses of A0-60/NBR Composites. Polym. Eng. Sci., 2019, 5(59), 949-955.

3. Malas A., Pal P., Das C.K., Effect of expanded graphite and modified graphite flakes on the physical and thermo-mechanical properties of styrene butadiene rubber/polybutadiene rubber (SBR/BR) blends. Mater. Design, 2014, 55, 664-673.

4. Chu H.H., Lee C.M., Huang W.G., Damping of vinyl acetaten-butyl acrylate copolymers. J. Appl. Polym. Sci., 2004, 91(3), 1396-1403.

5. Ngai K.L., Plazek D.J., Thermo-rheological, piezo-rheological, and TV $\mathrm{\gamma}$-rheological complexities of viscoelastic mechanisms in polymers. Macromolecules, 2014, 47(22), 8056-8063. 
6. Gusev A.A., Feldman K., Guseva O., Using elastomers and rubbers for heat-conduction damping of sound and vibrations. Macromolecules, 2010, 43(5), 2638-2641.

7. Zhao F.S., He G.S., Xu K.M., Wu H., Guo S.Y., The damping and flame-retardant properties of poly(vinyl chloride)/chlorinated butyl rubber multilayered composites. J. Appl. Polym. Sci., 2015, 132(2), 41259

8. Karamdoust S., Bonduelle C.V., Amos R.C., Turowec B.A., Guo S., Ferrari L., et al., Synthesis and properties of butyl rubberpoly (ethylene oxide) graft copolymers with high PEO content. J. Polym. Sci. Pol. Chem., 2013, 51(16), 3383-3394.

9. Grates J.A., Thomas D.A., Hickey E.C., Sperling L.H., Noise and vibration damping with latex interpenetrating polymer networks. J. Appl. Polym. Sci., 1975, 19(6), 1731-1743.

10. Zhang J.H., Wang L.F., Zhao Y.F., Understanding interpenetrating-polymer-network-like porous nitrile butadiene rubber hybrids by their long-period miscibility. Mater. Design, 2013, 51, 648-657.

11. Xu K.M., Zhang F.S., Zhang X.L., Hu Q.M., Wu H., Guo S.Y., Molecular insights into hydrogen bonds inpolyurethane/ hindered phenol hybrids: evolution and relationship with damping properties. J. Mater. Chem. A, 2014, 2(22), 8545-8556.

12. Song M., Zhao X.Y., Chan T.W., Zhang L.Q., Wu S.Z., Microstructure and dynamic properties analyses of hindered phenol A0-80/ nitrile-butadiene rubber/poly (vinyl chloride): a molecular simulation and experimental study. Macromol. Theor. Simul., 2015, 24, 41-51.

13. Qiao B., Zhao X.Y., Yue D.M., Zhang L.Q., Wu S.Z., A combined experiment and molecular dynamics simulation study of hydrogen bonds and free volume in nitrile-butadiene rubber/ hindered phenol damping mixtures. J. Mater. Chem., 2012, 22, 12339-12348.

14. Zhu J., Zhao X.Y., Liu L., Yang R.N., Song M., Wu S.Z., Thermodynamic analyses of the hydrogen bond dissociation reaction andtheir effects on damping and compatibility capacities of polar smallmolecule/nitrile-butadiene rubber systems: Molecular simulation andexperimental study. Polymer, 2018, 155, 152-167.

15. Wu C.F., Yamagishi T.A., Nakamoto Y., Ishida S.I., Nitta K.H., Kubota S., Viscoelastic Properties of an organic hybrid of chlorinated polyethylene and a small molecule. J. Polym. Sci. Pol. Phys., 2000, 38(10), 1341-1347.

16. Wu C.F., Mori K., Otani Y., Namiki N., Emi H., Effects of molecule aggregation state on dynamic mechanical properties of chlorinated polyethylene/hindered phenol blends. Polymer, 2001, 42(19), 8289-8295.
17. Zhao X.Y., Xiang P., Tian M., Fong H., Jin R., Zhang L.Q., Nitrile butadiene rubber/hindered phenol nanocomposites with improved strength and high damping performance. Polymer, 2007, 48, 6056-6063.

18. Zhao X.Y., Cao Y.J., Zou H., Li J., Zhang L.Q., Structure and dynamic properties of nitrile-butadiene rubber/hindered phenol composites. J. Appl. Polym. Sci., 2012, 123, 3696-3702.

19. Zhao X.Y., Zhang G., Lu F., Zhang L.Q., Wu S.Z., Molecular-level insight of hindered phenol AO-70/nitrile-butadiene rubber damping composites through a combination of a molecular dynamics simulation and experimental method. RSC Adv., 2016, 6(89), 85994-86005.

20. Song M., Zhao X.Y., Li Y., Hu S.K., Zhang L.Q., Wu S.Z., Molecular dynamics simulations and microscopic analysis of the damping performance of hindered phenol A0-60/nitrile-butadiene rubber composites. RSC Adv., 2014, 4(13), 6719-6729.

21. Song M., Zhao X.Y., Li Y., Chan T.W., Zhang L.Q., Wu S.Z., Effect of acrylonitrile content on compatibility and damping properties of hindered phenol A0-60/nitrile-butadiene rubber composites: molecular dynamics simulation. RSC Adv., 2014, 4(89), 48472-48479.

22. Song M., Wang X.J., Yu G.M., Cao F.Y., Zhang Y.L., Pei H.Y., et al., The dynamic properties of hindered amine GW-944/nitrilebutadiene rubber hybrid damping materials. Mat. Sci. Eng., 2019, 585(1), 012042.

23. Xu K.M., Zhang F.S., Zhang X.L., Hu Q.M., Wu H., Guo S.Y., Molecular insights into the damping mechanism of poly(vinyl acetate)/hindered phenol hybrids by acombination of experiment and moleculardynamics simulation. RSC Adv., 2015, 5(6), 4200-4209.

24. Xiang P., Zhao X.Y., Xiao D.L., Lu Y.L., Zhang L.Q., The structure and dynamic properties of nitrile-butadiene rubber/poly(vinyl chloride)/hindered phenol crosslinked composites. J. Appl. Polym. Sci., 2008, 109(1), 106-114.

25. Zhang J.H., Wang L.F., Zhao Y.F., Fabrication of novel hindered phenol/phenol resin/nitrile butadiene rubber hybrids and their long-period damping properties. Polym. Composite, 2012, 33(12), 2125-2133.

26. Zhu J., Zhao X.Y., Liu L., Song M., Wu S.Z., Quantitative relationships between intermolecular interaction and damping parameters of irganox-1035/NBR hybrids: Acombination of experiments, molecular dynamics simulations, and linear regression analyses. J. Appl. Polym. Sci., 2018, 135(17), 46202.

27. Yin C., Zhao X.Y., Zhu J., Hu H.H., Song M., Wu S.Z., Experimental and molecular dynamics simulation study on the damping mechanism of $\mathrm{C} 5$ petroleum resin/chlorinated butyl rubber composites. J. Mater. Sci., 2019, 54, 3960-3974. 